\title{
Dos escombros à gestação da palavra: José Saramago e Gonçalo Tavares em Diálogos Simbólicos
}

Paulo Ricardo Kralik Angelini

\section{Resumo}

José Saramago e Gonçalo M. Tavares possuem uma arquitetura narrativa bastante diferenciada. Talvez, quase opostas. Um é barroco, ornamentado; o outro é econômico, áspero. Enquanto o primeiro possui como marca indelével a presença de um narrador intruso, excessivo, demiurgo, o segundo faz geralmente uma literatura mais seca, menos digressiva, com frases curtas e de forte impacto. Entretanto, há um José Saramago pouco lido (e estudado), ainda anterior à descoberta do seu narrador conhecido em 1980. É a voz narrativa de O ano de 1993, que traz uma ambientação apocalíptica, que pode ser aproximada à obra Um homem: Klaus Klump. Os dois narradores edificam textos que comungam de uma mesma simbologia, especialmente relacionada à desfiguração do espaço, à derrocada, ao caos, em tempos de guerra. Este artigo analisa, sob a luz dos estudos do Imaginário, especialmente apoiado em Gilbert Durand e Gaston Bachelard, a destruição espacial e as imagens recorrentes $e$, por vezes, complementares, perceptíveis em "O ano de 1993" $e$ "Um homem: Klaus Klump”.

Palavras-chave: espaço; teorias do imaginário; símbolo; narrador; guerra. 
amar até o nosso último sopro.

Vivamo-la respirando-a.

Gaston Bachelard

Ao revisitarmos os textos de José Saramago, vêm-nos à mente um grande projeto ficcional em que o seu narrador, muito provavelmente, tenha sido o seu personagem mais notável. Em um mundo de Blimunda, Pedro Orce, Mau-Tempo, Raimundo, mulher do médico, Salomão e até Jesus Cristo, seres de papel que ganham vida através da pena saramaguiana e entram na galeria de personagens inesquecíveis, é a recorrência da cristalização dessa voz narrativa, ganhando corpo e seduzindo leitores, que tanto chama a atenção. José Saramago certa vez afirmou: "Quanto ao narrador, o que poderá ele ser senão uma personagem mais de uma história que não é a sua?" (SARAMAGO, 1997, p. 41). Bem verdade, o autor sempre mitificava seu próprio exercício narrativo, afirmando inclusive a inexistência da figura do narrador, confundindo autor empírico, autor implícito, voz narrativa: “Também não vale a pena dizer que o narrador é uma espécie de alter ego meu. Eu iria talvez mais longe e possivelmente com indignação de todos os teóricos da literatura, afirmaria: 'Narrador não sei quem é.' [...] No meu caso particular é como se estivesse a dizer ao leitor: 'vai aí o livro, mas esse livro leva uma pessoa dentro" (SARAMAGO apud MADRUGA, 1998, p.132-133).

Sim, Saramago carrega dentro de suas obras uma voz narrativa em constante diálogo com o leitor, construindo um narrador hiperbólico, demiurgo. Porém, essa tendência que temos de associar a obra de José Saramago ao seu narrador tão peculiar e conhecido enfraquece-se quando nos deparamos com um texto como $O$ ano de 1993, escrito antes da 'descoberta' da sua voz narrativa com Levantado do Chão, de 1980. Num caminho distinto dessa literatura barroca saramaguiana, de excessos, mas muito próximo da linguagem 'econômica' de $O$ ano de 1993, Gonçalo Tavares constrói seus textos com uma linguagem mais crua, mais seca, menos digressiva, especialmente em seus dois projetos literários mais conhecidos: os livros pretos (dentre os quais se destaca, além de Um homem: Klaus Klump, a obra Jerusalém) da tetralogia“O reino" e a bem-humorada série "O Bairro".

Com aproximadamente 30 anos de distância entre a publicação de O ano de 1993 (em 1975) e de Um homem: Klaus Klump (em 2003), ambas apresentam um surpreendente diálogo, e até uma certa complementariedade, compartilhada na construção de imagens próximas e de um simbolismo catastrófico.

Texto híbrido, de indecisão estrutural, como bem nos lembra Maria Alzira Seixo (SEIXO, 1987), de escrita versicular, O ano de 
1993 chegou a ser apontado por alguns críticos como uma última obra de poemas. Escrito antes da revolução dos cravos de 1974, na antemanhã da virada na vida política lusitana, traz, por isso mesmo, uma série de simbologias que se ligam a um aniquilamento do espaço e do homem que nele habita, espaço esse indeterminado, metafórico, uma "cidade doente de peste" (SARAMAGO, 2007, p.11), mas que pode também ser identificado junto ao longo e tortuoso período salazarista português. Já Um homem: Klaus Klump apresenta personagens igualmente em meio à dilaceração do ambiente, desta feita causada pela guerra. "Estamos em guerra" (TAVARES, 2007, p.46) nos alerta o narrador. A guerra é a própria peste. A imagem da putrefação, a partir de um cavalo morto, abandonado no meio da rua, remete aos ratos mortos espalhados pela cidade, em A Peste, de Albert Camus. Em Gonçalo Tavares, o cadáver desse cavalo marca um novo tempo em substituição à rotina tranquila e pacífica de outrora: "Ninguém toca num cavalo morto que está na rua há mais de uma semana. As moscas tocam no cavalo morto [...] Está no meio da rua, já não passam carros, já não passam casais simpáticos de sombrinha na mão" (Ibidem, p. 26). A imagem desse cavalo potencializa a decadência daquele ambiente. A presença, dia a dia, do animal morto na rua encena uma morte contínua, uma morte coletiva, a morte em tempo de guerra: "O cavalo morto prossegue a morrer ainda mais na rua. Milhares de moscas, existem milhares de moscas que se juntam. Ninguém tem curiosidade de ver como se transforma o que era um cavalo numa coisa estranhamente quente, mas nojenta" (Ibidem, p.32). Esse cavalo é a própria marcação do tempo, da guerra, e do tempo de guerra, pois, como nos diz o narrador: "antes de os tanques entrarem e de o cavalo estar meses a apodrecer no centro da rua" (Ibidem, p.42).

Gilbert Durand, na obra As estruturas antropológicas do Imaginário, afirma que a mitologia e a literatura têm associado o cavalo a diferentes imagens, entre elas, de forma bastante recorrente, a do tempo, porque "deusas lunares dos gregos, escandinavos e persas viajam em veículos puxados por cavalos. O cavalo é, portanto, o símbolo do tempo, já que se liga aos grandes relógios naturais" (DURAND, 2002, p.78). Por conseguinte, pode-se relacionar o cavalo na obra de Gonçalo Tavares a um tempo que se deteriora em sua própria síntese.

Para a configuração do espaço de $O$ Ano de 1993, a voz narrativa pede auxílio a Salvador Dalí, que construiu "a imagem necessária para os dias de 1993" (SARAMAGO, 2007, p.7). Neste tempo mítico, estagnado, em que o sol não se move, surge a imagem: "As pessoas estão sentadas numa paisagem de Dalí com as sombras muito recortadas por causa de um sol que diremos parado" (Ibidem, p.7).Também Tavares traz uma outra metáfora sobre este tempo que se quebrou: "Há um muro entre o ano passado e hoje. Um muro altíssimo: ninguém percebe o que sucedeu: como 
se constrói um muro no tempo?" (TAVARES, 2007, p.26), o que provoca uma dissipação do passado, da memória, da história de uma comunidade, agora invadida pelo inimigo. A descrição desse cenário traz um ambiente devastador, repleto de contornos, mas também lacunar, uma vez que "uma enorme ausência guarda as portas da cidade" (SARAMAGO, 2007, p.22). Diz o narrador de Saramago:

Este dia em que as pessoas estão sentadas na paisagem entre dois prumos de madeira que foram uma porta sem paredes para cima e para os lados Não há portanto casa nem sequer a porta que poderia não abrir precisamente por não haver para onde abrir. Apenas o vazio da porta e não a porta (Ibidem, p.8).

Similar imagem de obra incompleta, porque destruída, é trazida por Gonçalo Tavares: “O país está inacabado como uma escultura: vê a geografia de um país: falta-lhe terreno, escultura inacabada: invade o país para finalizares a escultura. Guerreiro-escultor" (TAVARES, 2007, p.7). Esta forma plástica inacabada é também representação de um tempo mítico, de pré-geografia, uma vez que "depois da História não há geografia" (Ibidem, p.7). Ou seja, a partir dessa constelação fatídica de traços de civilização humana ocorre o aniquilamento do espaço. Diz ainda o narrador, acentuando um efeito devastador na narrativa: "O massacre visto de cima: escultura. Todos os restos de corpos podem ser o início de outros assuntos" (Ibidem, p.7).

Um lugar arrasado que exige novas técnicas de sobrevivência. Homens e cães começam a viver também nas profundezas da terra: em O ano de1993, "Certos homens embora não adaptados morfologicamente passaram a viver debaixo do chão" (SARAMAGO, 2007, p.41) e, em Um homem: Klaus Klump, "Com força arrancou do solo um cão. Não era uma pequena árvore, era um cão" (TAVARES, 2007, p.7). Natureza transformada, os homens tornam-se primitivos, conta-nos o narrador de Tavares. Nos confinamentos da guerra: "a civilização termina ali: os presos eram antigos, havia crimes de família; vivos metade loucos" (Ibidem, p.38). Em Saramago, este homem quase que volta ao Paleolítico e desenha nas cavernas imagens bélicas: "E nas paredes de uma gruta alguns homens reproduziram o leão e os corvos voando e ao fundo uma cidade armada" (SARAMAGO, 2007, p.99). O humano também animaliza-se: "um homem aguarda que lhe cresçam as unhas o suficiente Para espetando-as nos olhos chegar com elas ao côncavo do outro lado do crânio" (Ibidem, p. 13-14). Essa animalização provoca uma inversão na lógica: "Na cidade apenas vivem os lobos. Deste modo se tendo invertido a ordem natural das coisas estão os homens fora e os lobos dentro" (Ibidem, p.22). Homens que viram bichos, em uivos e gritos de dor. Para a imaginação ocidental, segundo Gilbert Durand, o lobo é esse animal feroz, temido por toda a Antiguidade e pela Idade Média, personagem de contos 
assombrosos, "símbolo infantil de medo, pânico, de ameaça, de punição. [...] Num pensamento mais evoluído, o lobo é assimilado aos deuses da morte e aos gênios infernais" (DURAND, 2002, p.86). Os homens fogem dos lobos, os homens fogem da morte. A tentativa de sobrevivência torna esses dias repetitivos. Diz-nos um personagem de Gonçalo Tavares: "Enquanto estamos vivos o dia é igual. É isto. Sobreviver. Continuar a querer estar vivo" (TAVARES, 2007, p.81). Na cartilha da guerra, o ódio realimenta-se e transforma a mulher em moeda de uso, em ambas as obras. Em Tavares: "Os homens que são mais fortes violam as mulheres que ficaram atrás, mulheres dos inimigos que fugiram" (Ibidem, p.9), e em Saramago: "Será visto que estando mortos os homens perseguidos hão-de violá-las conforme mandam as imemoriais regras da guerra" (SARAMAGO, 2007, p.34).

Os elementos da natureza compactuam e reforçam essa atmosfera catastrófica. Os animais de estimação rebelam-se em O ano de 1993 e agora praticam atos de violência e tortura:

A primeira vítima de que houve notícia foi a mulher do governador escolhido pelo ocupante Quando o macaco amestrado que a divertia nas horas de aborrecimento a crucificou no portão do jardim enquanto as galinhas saíram da capoeira para vir arrancar-lhe à bicada as unhas dos pés (Ibidem, p.49).

Também as crianças ficaram cegas, tendo perfuradas as vistas por aves "que se atiravam dos ramos e das alturas como pedras" (Ibidem, p.50).

A terra não mais produtiva, seca, morta, representa o esgotamento de fontes naturais. Em Um homem: Klaus Klump, quase não há mais verde: "Há demasiado asfalto neste país. Os homens corajosos já não têm bosque suficiente para se esconderem" (TAVARES, 2007, p.11). "E o mar já não existe", pois a guerra o transformou em uma vastidão agonizante, em que os peixes adoecem. Gilbert Durand aponta que, no Imaginário, "o mundo da água é também sob muitos pontos de vista, objeto de uma esperança fundamental" (DURAND, 2002, p.234), o que reafirma, na obra de Gonçalo Tavares, a intensidade desse caótico desesperançado. Este mar, princípio e fim de todas as coisas, na obra de Saramago surge como espaço de lamentações, em imagem que remete a novos velhos de Restelo:

Agora os homens apenas procuram o mar para se lamentarem diante da grande voz das ondas E postos de joelhos em linha com os braços abertos recebendo no rosto a fustigação do vento e da espuma Gritam ensurdecidos pelo estrépito a miséria extrema que por agora os dispersa na terra (SARAMAGO, 2007, p.58-59).

Durand ainda afirma que "as águas seriam as mães do mundo, enquanto a terra seria a mãe dos seres vivos e dos homens" (DURAND, 2002, p.230). Nas duas obras, essa mãe já é estéril, 
uma vez que tanto o mar quanto a terra estão devastados, o que mais uma vez sublinha a imagem de pessimismo. "O cadáver está condenado à terra. A terra condenada ao cadáver" (TAVARES, 2007, p.74). Essa terra que é ventre materno, de onde saem os homens, em Saramago está coberta por sujeira e fezes.

Não é difícil chegar basta olhar o chão e seguir sempre pelos caminhos mais pisados também reconhecíveis pelas duas alas de excrementos que os ladeiam $\mathrm{O}$ sol resseca-os rapidamente e se a chuva os desfaz nunca tanto que restitua o chão a uma qualquer virgindade (SARAMAGO,2007, p.26).

Bachelard chama a atenção para a imagem do esterco, explorada por Saramago: "O esterco possui assim uma espécie de força atrativa para tudo aquilo que é impuro, o esterco é um abcesso de fixação para a impureza das sementes" (BACHELARD, 2001, p.201). Igualmente na obra de Tavares há a presença da impureza, uma vez que as pessoas estão sujas, porque "ninguém permanece limpo: a guerra dura há tempo de mais [...]. A única higiene que nos importa é sobreviver" (TAVARES, 2007, p.81).

Esta atmosfera de podridão também traz, em Um homem: Klaus Klump, um mundo metalizado, pois "há infiltrações de metal por toda a cidade. Antes havia aquilo a que chamavas pequenos jardins. $\mathrm{O}$ cinzento enquanto cor é bem mais guerra do que o verde" (Ibidem, p.41). A cor do metal translúcido também aparece em $O$ ano de 1993: "Enquanto os lingotes de ouro brilham sob uma luz que misteriosamente não se apagou Como uma espécie de podridão fosforescente e venenosa" (SARAMAGO, 2007, p.15).

Para Gaston Bachelard, na obra A terra e os devaneios da vontade, a solidez metálica revela uma existência absoluta e é a representação da frieza: "A hostilidade do metal é assim o seu primeiro valor imaginário. Duro, frio, pesado, anguloso, ele tem tudo o que é preciso para ser ofensivo, psicologicamente ofensivo" (BACHELARD, 2001, p.191).

É a imagem da agressividade, ativada pela robotização. Nas duas obras, esses elementos hostis estão em deslocamento, à caça das pessoas que circulam ou que se escondem. Os tanques de guerra na obra de Tavares, os animais mecânicos na de Saramago. Os animais são mortos, suas vísceras são retiradas para que seus cadáveres sejam providos "de poderosos mecanismos internos ligados aos ossos por circuitos eletrônicos" (SARAMAGO, 2007, p.66). Esses animais mecânicos, esses seres-máquinas são grandes predadores, e só "existem para prosseguir o extermínio da população ocupada" (Ibidem, p.78). O narrador de Tavares resume essa ideia: "Na paisagem as máquinas substituíram os animais" (TAVARES, 2007, p.33). Gaston Bachelard traz uma síntese assaz pertinente às duas obras, quando se refere ao mundo metal: "o mundo inteiro com seus seres ativos é visto sob as espécies metálicas. O ser existe em toda a sua força, quando foi revestido 
metalicamente, organizado metalicamente" (BACHELARD, 2001, p.141).

A desolação do espaço arrasado por onde transita Klaus Klump traz animais mortos em decomposição, insetos e esses bichos da guerra, tanques metálicos que passeiam por onde antes a vida passava. A população defende-se como pode. Esses homens que se tornaram primevos, armam-se de paus e de pedras. Em $O$ ano de 1993: "Nenhumas armas a não ser os toscos paus arrancados dificilmente aos ramos mais baixos das árvores e as pedras roladas colhidas nos leitos das ribeiras" (SARAMAGO, 2007, p.97). Klaus Klump também usa como arma de defesa uma pedra, e o narrador diz que ela só "servirá para matar doentes ou velhos. Ou crianças. É uma arma incompetente, toda a técnica é incompetente em guerra se não mata com certa eficácia e rapidez inimigos robustos" (TAVARES, 2007, p.76). A pedra como arma revela não apenas o já mencionado primitivismo do homem, mas também sua fragilidade frente a um inimigo mais forte. A sobrevivência só vem, portanto, com a submissão: "A vida em guerra só tem dois sentidos: com eles ou contra eles. Se não queres morrer beija as botas do mais forte," (Ibidem, p.13), porque "quem é fraco cai e faz o que o forte quer" (Ibidem, p. 12). É um mundo apocalíptico que dilacera: "O mundo por vezes amputa um braço dos homens que estão do lado de fora da janela. Vê o mundo, o mundo tem uma lâmina" (Ibidem, p. 13).

Contudo, esse mundo hostil e maquinal revela pequenas cenas de contraditória beleza poética, como a do miúdo, na obra de Tavares, que observa um enorme tanque à sua frente e lembra-se do aconchego de um lar que lhe foi arrancado, imagem que nos remete à emblemática fotografia de Jeff Widener, na qual um solitário homem interrompe uma fileira de tanques na China:

Havia na casa uma máquina de café que fazia ruídos desnecessários e essa máquina desapareceu; a criança olha para cima, para o tanque, e acredita que aquela máquina veio substituir a máquina de café que foi roubada em casa. E foi roubada com o pai. Esta máquina vai trazer o café e o meu pai (Ibidem, p. 33).

Nas duas obras, mesmo o som é metálico. Na de Saramago: "Quando o sol nasceu ouviu-se do lugar onde a tribo ficara um enorme tumulto um estridor de gritos e asas e uivos de metal" (SARAMAGO, 2007, p.82). Qualquer resquício de música melodiosa é substituído pelo som da guerra. Na de Tavares: "Os tanques entravam na cidade. $\mathrm{O}$ som militar entrava na cidade e a música calma escondia-se na cidade" (TAVARES, 2007, p.8); "Uma sirene toca. Uma sirene militar não é um instrumento pacífico que faça dançar as mulheres. Aquela sirene fazia chorar as mulheres" (Ibidem, p.30). O ruído das sirenes e dos tanques em Tavares, o barulho dos animais mecânicos e do toque de recolher em Saramago caracterizam o caótico de uma civilização que se desumaniza, 
"porque o barulho das balas, das granadas: nada desses sons disformes tem sequer o mínimo de vestígio verbal: não é humano, claramente, esse som" (Ibidem, p.86). Não é humano e nem natural: "Ruído. Este não é o som da leitura, disse. Nem o som natural do céu" (Ibidem, p.9), pois traz uma atmosfera poluída com aviões de guerra - "Os aviões infiltravam-se na natureza alta e assustavam" (Ibidem, p.9). A triste sinfonia que ecoa nesses espaços devastados não é propícia ao pensamento livre, intelectualizado, libertador. Ao contrário, essa música metalizada aprisiona, "é um sinal forte de humilhação. Se quem chegou impõe a sua música é porque o mundo mudou, e amanhã serás estrangeiro no sítio que antes era a tua casa" (Ibidem, p.20).

A dominação se dá em diferentes frentes, e por vezes a ausência do som apavora tanto quanto a sua presença, pois reforça a ideia de terra arrasada: "E a rua tem aquele excesso de silêncio que há no que foi habitado e agora não" (Ibidem, p.85). O narrador de Tavares continua: "Cada povo tem direito à sua música e ao silêncio. Tem direito a decidir de que modo quer interromper o silêncio. Direito a escolher que sons quer" (Ibidem, p.20). Não em tempo de guerra. Não em tempo de totalitarismo. Em tempos assim, vem o grito desesperado, como em Saramago: "Os homens gritam ensurdecidos pelo estrépito a miséria extrema que por agora os dispersa na terra" (SARAMAGO, 2007, p.59). Tanto Bachelard quanto Durand sublinham a aproximação entre a música primitiva e o ruído concreto. Há culturas que fazem como rituais de bramidos comemorando um sacrifício. Já no universo de Klaus Klump é a literatura, o mergulho num mundo outro, de criação, que pode afastar esses sons mecânicos: "Atraído pela literatura, tinha-se afastado dos sons a que chamava primitivos, esses sons que vêm do exterior e de longe" (TAVARES, 2007, p.86), pois é "preciso ser muito indiferente às palavras para poder dar a sua atenção grande aos sons" (Ibidem, p.29).

Outros sons também ressoam, mas apenas na imaginação de Klaus Klump: o som da relação entre um homem e uma mulher: "sons que as mulheres faziam no ato amoroso. Barulhos verbais excitados" (Ibidem, p.85). E conclui sua tese, afirmando que: "um barulho verbal era, de fato, um fenômeno estranho. O barulho [...] atira de imediato para o mundo animal, mundo grotesco, mundo de deficiência que não se consegue exprimir; e o verbal associado a esta disformidade impõe estranheza" (Ibidem, p.85). O animalesco provoca grunhidos. Durand, lembrando Bachelard, mostra que o "grito inumano está ligado à boca das cavernas, à boca de sombra da terra, às vozes cavernosas incapazes de pronunciar vogais doces" (DURAND, 2007, p.85). Este grito animal de voracidade ressoa pela terra arrasada tal qual uma música triste: "Embora se afirme que em um dos milhares de compartimentos do edifício uma mulher ainda não parou o mais longo gemido da história do mundo" (SARAMAGO, 2007, p.13). E outra vez Durand: 
"É portanto na goela animal que se vêm concentrar todos os fantasmas terrificantes da animalidade: agitação, mastigação agressiva, grunhidos e rugidos sinistros" (DURAND, 2002, 85).

$\mathrm{O}$ ato sexual, esse encontro possível entre dois corpos, mais violento que afetivo, traz essas reminiscências instintivas e direciona-se para um microcombate às forças opressivas. É o resultado de duas vontades, que desafiam o autoritarismo e libertam-se ao toque. Em $O$ ano de 1993, em meio à terra seca, um homem e uma mulher adentram uma floresta, espaço adequado para a relação. "Quase noite o homem e a mulher que se tinham escolhido para sempre afastaram-se na direção de uma floresta que fechava o céu" (SARAMAGO, 2007, p.80).

Bachelard, em A poética do Espaço, traz a paradoxal simbologia da floresta, essa imensidão íntima que apresenta uma grandeza oculta e, ao mesmo tempo, um aconchego: “Não é preciso permanecer muito tempo nos bosques para conhecer a impressão sempre um pouco ansiosa de que mergulhamos num mundo sem limites" (BACHELARD, 2000, p.191). A floresta é espaço de transcendência psicológica. Ainda que faça barulho, os ruídos da floresta provocam um silêncio transcendente, pois todo um arsenal de sons é apagado pela música do bosque - "A floresta é um estado de alma" (Ibidem, p.192). Essa vastidão verde, que para Gilbert Durand "desempenha um papel terapêutico porque é assimilado à calma, ao repouso, à profundidade materna", (DURAND, 2002, p.221) é o cenário ideal para que esse homem e essa mulher, na obra de Saramago, sem dizerem palavra alguma, acabem por se abraçar. Um efeito mágico ocorre então naquele espaço. A árvore que lhes servia de abrigo abriu-se e: "recebeu-os dentro de si juntando a seiva e o sangue Todas as aflições se acabaram naquele instante e a chuva escorria pelas folhas e pelos troncos como alimento até ao chão que as raízes lentamente trabalhavam" (SARAMAGO, 2007, p.82). Árvore que se faz morada. Para Durand, "a árvore tem um simbolismo cíclico, encontra-se associada às águas fertilizantes, é árvore da vida" (DURAND, 2002, p.339). Essa árvore que orienta um devir "representará o produto do casamento, a síntese dos dois sexos: o filho" (Ibidem, p.341). É, portanto, o futuro, imagem até então impossível em ambas as obras.

Esta junção do humano com a natureza principia um movimento de libertação. A árvore que se juntou ao homem e à mulher personifica-se e torna-se combativa: "No ano de 2093 ainda se contará que cem anos antes foi vista uma árvore sair da floresta andando sobre as raízes e fazer dos seus ramos laços e lanças e dardos das folhas agudas" (SARAMAGO, 2007, p.82). A árvore que uniu o homem e a mulher traz um princípio de reconstrução deste mundo arrasado, e a partir de outros Adão e Eva, faz-se coletividade e une-se ao nascimento de um novo tempo: 
E também se dirá que depois para onde fosse a tribo ia a árvore caminhando sobre as raízes E que debaixo dela se abrigavam à noite ou quando o sol queimava os outros homens e as outras mulheres que nos primeiros dias ainda recordaram os companheiros para sempre desaparecidos naquela noite em que a morte fora o destino certo da tribo (Ibidem, p. 83).

Em uma cena da obra de Gonçalo Tavares, um soldado violenta uma mulher. Como testemunha, há uma árvore solitária e resistente: "É sexta-feira, e uma árvore ainda está no jardim, apesar de existirem tanques a passar nas ruas" (TAVARES, 2007, p.9). Klaus Klump sublinha, ainda, no ato sexual, outra vez uma associação homem-animal: "E daí que a fornicação seja tão atrativa e assustadora: é a junção de dois mundos: do mundo do ruído e do mundo da palavra, do mundo do Homem e do animal, da natureza incompreensível e bruta e ainda o Homem que tenta compreender" (Ibidem, p. 85).

É na redescoberta de uma harmonia com a natureza, não mais hostil nem brutal, que renascerá este novo tempo. Outra cena bastante simbólica na obra de Saramago é aquela em que alguns homens tornam-se adeptos a certas práticas mágicas de tempos remotos, a saber:

Nos campos cultivados faziam correr as mulheres menstruadas para que o sangue escorrendo ao longo das pernas embebesse o chão com sangue de vida e não de morte Nuas corriam deixando um rasto que os homens cobriam cuidadosamente de terra para que nem uma gota secasse sob o calor agora nocivo do sol (SARAMAGO, 2007, p.102).

Este ritual procura recuperar a força maternal da terra, num lugar em que há muito tempo não nasciam crianças. É quando surge uma mulher grávida: "E um dia vinda de longe uma mulher grávida quase no fim do tempo chegou e pediu que a deixassem ficar ali Porém preciosa era aquela criança que estava para nascer" (Ibidem, p.102). O nascimento acelera um movimento de frutificação em série, uma vez que "alguns dias mais tarde nasceu uma criança e houve as melancólicas festas de então e todas as mulheres se declararam grávidas E desta maneira tudo começou naquele lugar e não noutro com aquela gente e não outra apenas com o presente e o futuro não o passado" (Ibidem, p.103).

Além da natureza que refloresce, em novos ciclos, rumo a um futuro, há um outro e fundamental renascimento: o da palavra, processo que se manifesta de forma aflitiva: "Para começar o outra vez doloroso nascimento duma primeira palavra" (Ibidem, p.88). Nas duas obras, em tempo de guerra e de opressão, a palavra foi sitiada, esquecida, desdenhada: "A cidade que os homens deixaram de habitar está agora sitiada por eles Não deve passar em claro o exagero que há na palavra sitiada Como exagero haveria na palavra cercada ou outra qualquer sinônima" (Ibidem, p.21). Em O ano de 1993, um homem percebe-se sem linguagem: "Mas foi de 
noite na negrura aflita da caverna lá onde só o olho vermelho das brasas tinha pena dos homens [...] que subitamente um homem descobriu que não sabia ler. Em vão recordava as letras em vão as desenhava ele próprio na memória" (Ibidem, p.62). Igualmente na obra de Gonçalo Tavares os tanques, personificados, trazem uma outra língua, incompreensível: "Os tanques passam nas ruas. As ruas têm o nome dos nossos heróis. Eles não conhecem a língua: não sabem dizer o nome. Tropeçam na pronúncia, não conseguem acentuar as sílabas. E os tanques não têm tempo para aprender línguas" (TAVARES, 2007, p.10). Esta palavra estrangeira é proibida, não pode ser aprendida: "certos homens diziam às irmãs: deves defender a pronúncia como defendes a vagina. Não repitas uma única palavra deles" (Ibidem, p.21), porque "se há mais pessoas a falar outra língua em cima de um lugar esse lugar muda: são os sons que mais mudam um lugar" (Ibidem, p.64). A palavra nacional dentro da guarita, porque a guerra varre a palavra para longe, porque os tanques "limpam a linguagem das praças e dos cafés, e limpam a linguagem porque quando os tanques passam os homens falam baixo..." (Ibidem, p.10). Contudo, as mordaças impostas fazem a palavra esvaziar-se: "As frases tinham perdido o lado exato antigo. Já não discursava certo e de uma vez. As frases eram aproximações, tentativas" (Ibidem, p.25); "as palavras mudam pouco, o vocabulário em situações extremas não é composto por mais de 50 elementos" (Ibidem, p.45). O narrador de Um homem: Klaus Klump é declarativo: "A linguagem é mais utilizada em tempo de paz, sobre isso não há dúvida: em tempo de guerra não há conversas, apenas informações. Frases rápidas e curtas" (Ibidem, p.109).

Em tempo de guerra, há o som metálico, a palavra estrangeira e o silêncio da mordaça. Em tempo de guerra, a perda da palavra é o aniquilamento da identidade: "Klaus tinha os lábios pretos, como se falasse outra língua. Tinha perdido a pátria e com ela cada palavra antiga tinha-se tornado escandalosa. São palavras pretas. Queimavam os lábios" (Ibidem, p.60).

Uma repatriação passa, pois, pelo fazer poético.

Atraído pela literatura tinha-se afastado dos sons a que chamava primitivos, esses sons que vêm do exterior e de longe, quando se abre a janela, se em tempo de paz haviam sido os livros, em tempo de guerra eram as máquinas, neste caso as pequenas máquinas, que eram as armas, que o haviam afastado da natureza (Ibidem, p. 86)

Na obra de Saramago, igualmente há esse apagamento da linguagem e uma necessidade de reaprendê-la:

Não admira que fosse preciso reaprender a linguagem simplificada da fome e do frio E também as palavras da manhã e da noite e aquelas que determinam o céu a caminho das estrelas ou apenas o perfil da montanha Porque se sabiam as sensações e não as palavras que as 
A linguagem, a palavra, o futuro. $\mathrm{O}$ futuro na imagem da criança. Em Saramago, em meio ao horror da catástrofe um miúdo redescobre a magia da linguagem das sombras: "uma criança objectiva se aproxima e estende as mãos para a sombra que fragilmente retém o contorno" (Ibidem, p.124). O poético, o literário tornam-se atalhos para um tempo de sossego. Em meio ao caos, no universo de Klaus Klump, "as professoras agarram as crianças e dão-lhes conselhos sobre o modo de fugir mais rápido quando começarem os sons perigosos" (TAVARES, 2007, p.32). Em meio à carência alimentar, são as narrativas que milagrosamente pacificam, remédio imaginativo que apazigua: "uma criança tem fome e recebe um estalo da professora. A professora chora. A criança pede-lhe uma história. A professora conta-lhe a história e a criança adormece ao colo dela. Está cheia de fome e ainda adormece" (Ibidem, p.33).

É a palavra redescoberta que redireciona o nascimento deste futuro, o novo tempo que brota do solo: "Uma criança esconde um relógio debaixo da terra, num pequeno vaso. Para que a planta cresça a um ritmo certo, pensa ela. Um relógio enterrado na terra" (Ibidem, p. 108). É na força do poético que renascem as esperanças.

No Evangelho de São João, a palavra é explicitamente associada à luz que brilha nas trevas. Durand, lembrando Jung, afirma que "a etimologia indo-europeia de aquilo que luz é a mesma que a do termo que significa falar, e esta semelhança também se encontra em egípcio" (DURAND, 2002, p.154). A propósito, as duas obras fazem referência à Bíblia, ao encontro das imagens do Apocalipse. Em Saramago: "Porém segundo estava escrito em lendas antiquíssimas haveria vozes vindas do céu ou trombetas ou luzes extraordinárias e todos quiseram estar presentes Alguma coisa podia talvez suceder no mundo antes do triunfo final da peste nem que fosse uma peste maior" (SARAMAGO, 2007, p.11-12) e em Tavares: "Certas crianças adoecem, mas são curadas. Cita-se o Apocalipse: [...] e as folhas desta árvore servem para curar as nações" (TAVARES, 2007, p.108).

Faz-se o silêncio. "Tentemos pôr todo o nosso ser em silêncio - escutemos apenas o nosso sopro - tornemo-nos aéreos como o nosso sopro - não façamos mais barulho que um sopro, um leve sopro - imaginemos apenas as palavras que se formam a partir do nosso sopro..." (BACHELARD, 1990, p.247). Do sopro, faz-se a palavra. As palavras que são libertadoras. Outra vez lembramos Bachelard: "Quando essa palavra toma consciência de si, então a atividade humana deseja escrever, isto é, agenciar os sonhos e os pensamentos" (Ibidem, p.257).

Em Gonçalo Tavares, há um grupo de miúdos, folhas em branco e o desafio de escrever-se: "Os meninos com um cader- 
no em branco ficam contentes. O importante na infância são as tentativas" (TAVARES, 2007, p.10). Bachelard afirma que a linguagem escrita cria seu próprio universo - "um universo de frases se ordena sobre a página branca..." (BACHELARD, 1990, p.258). Um novo universo, desejos de mudanças, de transformação. É o súbito fim da guerra em Um homem: Klaus Klump: "A força que antes atirara o país para a guerra, a mesma força, impôs agora a paragem. E a guerra parou, quase da mesma forma brusca e surpreendente como havia começado. Só isto" (TAVARES, 2007, p.101). É a normalização do caos, o mundo mecânico que entra em colapso: "fim da comunicação os animais mecânicos são destruídos na queda os que voavam paralisados no movimento os que no chão se deslocavam e caídos para o lado" (SARAMAGO, 2007, p.98), a natureza que se reergue: "Levantou-se então um grande vento que varreu de estrema a estrema entre o mar e a fronteira a terra dos homens Durante três dias soprou constante arrastando as nuvens dos incêndios e o cheiro da carne morta dos invasores" (Ibidem, p.117).

Uma nova brisa de democracia que traz cenas tão conhecidas do imaginário português em abris passados: “Ó este povo que corre nas ruas e estas bandeiras e estes gritos..." (SARAMAGO, 2007, p.115). E segue: “Depois choveu e a terra ficou subitamente verde com um enorme arco-íris que não se desvaneceu nem quando o sol se pôs [...] E houve quem chorasse de joelhos na terra branda nas ervas que rescendiam do vertiginoso cheiro do húmus" (Ibidem, p.118).

A força das palavras, como nos lembra Bachelard, "há palavras que, apenas pronunciadas, apenas murmuradas, abrandam em nós os tumultos" (BACHELARD, 1990, p. 245). Palavras de libertação: "O dia amanheceu numa terra livre por onde corriam soltos e claros os rios" (SARAMAGO, 2007, p.120). Palavras que surgem como cantigas em Saramago "E houve quem ininterruptamente cantasse uma extática melodia não ouvida antes que era o longo suspiro soluço da vida que nascendo se sufoca plena na garganta" (Ibidem, p.118-119).

Respirar a palavra, como incita Bachelard. A palavra como arma, a palavra como ruptura. Nos diz o narrador de Tavares: "Isso não é um livro, é uma pequena bomba. Queres perturbar tanques com prosa? (TAVARES, 2007, p.11)

Sim, é possível destruir tanques com a prosa. É possível instigar seres calados, refazer caminhos, renascer esperanças. Bachelard nos diz que "os manifestos mais revolucionários são sempre novas constituições literárias. Fazem-nos mudar de universo, mas sempre nos abrigam num universo imaginário" (BACHELARD, 1990, p.258). Que se façam novos universos em que as histórias transformem o estado das coisas. Em que os silêncios forjados transmutem-se para o sopro poético. Como nos canta Saramago em $O$ ano de 1993: “Uma vez mais enfim o mundo o 
mundo algumas coisas feitas contadas tantas não e sabê-lo Uma vez mais o impossível ficar ou a simples memória de ter sido" (SARAMAGO, 2007, p. 125).

Uma vez mais, a palavra...

\begin{abstract}
José Saramago and Gonçalo M. Tavares display contrasting narratives. Perhaps almost opposite to each other. One is Baroque, ornate. The other is economical, rough. While Saramago has as indelible mark the presence of an excessive, demiurge narrator, Tavares chooses a drier, less digressive literature, with short, strong blowing sentences. Meanwhile, there is a less read (and studied) José Saramago prior to the discovery of his Narrator introduced in 1980. It's the narrative voice of $O$ ano de 1993, which offers an apocalyptic setting, resembling the literary work of Um homem: Klaus Klump. The two narrators build texts that share equal symbolism, in particular relating to the defacement of space, to collapse, to chaos in times of war. Under the light of the studies of the Imaginary, inspired by Gilbert Durand and Gaston Bachelard, this article explores spatial destruction and recurrent and, at times, complementary imagery perceptible in $O$ ano de 1993 and Um home: Klaus Klump.
\end{abstract}

Keywords: space; theory of the Imaginary; symbol; narrator; war.

\title{
REFERÊNCIAS
}

BACHELARD, G. A água e os sonhos. São Paulo: Martins Fontes, 1989.

. A poética do espaço. São Paulo: Martins Fontes, 2000. $5^{\mathrm{a}}$ ed. . A terra e os devaneios da vontade. São Paulo: Martins Fontes, 2001. $2^{\mathrm{a}}$ ed.

. O ar e os sonhos. São Paulo: Martins Fontes, 1990. $1^{\mathrm{a}}$ ed.

DURAND, G. As estruturas antropológicas do imaginário. São Paulo: Martins Fontes, 2002.

2000.

Imagens e reflexos do Imaginário Português. Lisboa: Hugin,

SARAMAGO, J. Do Canto ao Romance, do Romance ao Canto. Bulletin Of Hispanic Studies, 71, no. 1 (January 1994).

. O ano de 1993. São Paulo: Companhia das Letras, 2007. 
. O autor como narrador. In: Ler, 38, Primavera-Verão, 1997. . Paixões de um narrador obsessivo. In: MADRUGA, C. A paixão segundo José Saramago. Porto: Campo das Letras, 1998. p. 132-133. Entrevista compilada por Conceição Madruga.

SEIXO, M. A. O Essencial sobre José Saramago, Lisboa, Imprensa Nacional - Casa da Moeda, 1987.

TAVARES, G. M. Um homem: Klaus Klump. São Paulo: Companhia das Letras, 2007. 